\title{
RELAÇÕES AFETIVO-SEXUAIS E PREVENÇÃO CONTRA INFECÇÕES SEXUALMENTE TRANSMISSÍVEIS E AIDS ENTRE MULHERES DO MUNICÍPIO DE VITÓRIA - ES
}

\author{
Melissa Mattos Amorim \\ Ângela Nobre de Andrade
}

\begin{abstract}
RESUMO. Objetivou-se conhecer como mulheres vivenciam a prevenção de infecções sexualmente transmissíveis (IST) e aids em suas relações afetivo-sexuais. Foram realizados dois grupos de discussão e 12 entrevistas individuais com mulheres na faixa etária de 20 a 35 anos. Um grupo foi composto por cinco participantes com ensino fundamental ou médio (Grupo1) e o outro, por sete participantes com ensino superior completo ou incompleto (Grupo2). Apenas três participantes faziam uso consistente do preservativo masculino como medida preventiva de IST/Aids. O uso inconsistente do preservativo foi justificado pela presença, no contexto relacional, do compromisso de exclusividade sexual mútua. Valores e crenças acerca do conhecimento sobre o parceiro sexual e da confiança nele investida orientavam as percepções das participantes de ambos os grupos sobre a necessidade de adesão a medidas preventivas. Observou-se que tais percepções também estavam estreitamente vinculadas às suas relações e implicações de gênero.
\end{abstract}

Palavras-chave: prevenção, infecções sexualmente transmissíveis e Aids, gênero.

\section{SEXUAL RELATIONSHIPS AND INFECTIONS SEXUALLY TRANSMITTED AND AIDS PREVENTION AMONG WOMEN IN VITÓRIA-ES, BRAZIL}

\begin{abstract}
The aim of this study was to understand how women deal with Infections Sexually Transmitted (IST) and Aids prevention within the context of relationships. Two discussion groups and 12 individual interviews were carried out with women aged 20-35. One of the groups was formed by five participants, who attended school for a period inferior or equivalent to eight years (Group 1) and, the other, by seven university students or graduates (Group 2). Only three participants (two from Group 1 and one from Group 2) reported consistent use of condom as a preventive measure against IST/Aids. Sexual exclusivity between partners was the main explanation given for the inconsistent use of condom. Values and beliefs related to factors such as, knowing the sexual partners well and trust invested in them, guided participants' perceptions regarding the circumstances in which adhesion to preventive measures is necessary. Results also suggest that those perceptions were associated to the type of relationship and other implications regarding that.
\end{abstract}

Key words: Infections sexually transmitted and Aids, prevention, gender.

\section{RELACIONES AFECTIVO-SEXUALES Y PREVENCIÓN CONTRA INFECCIONES SEXUALMENTE TRANSMISIBLES Y SIDA ENTRE MUJERES DEL MUNICIPIO DE VITORIA-ES}

\begin{abstract}
RESUMEN. El propósito de este estudio fue conocer como mujeres vivencian la prevención de infecciones sexualmente transmisibles (IST) y SIDA en sus relaciones afectivo-sexuales. Fueron realizados dos grupos de discusión y 12 entrevistas individuales con mujeres en la franja de edad desde 20 hasta 35 años. Un grupo fue compuesto de cinco participantes con enseñanza fundamental o media (Grupo 1), y otro de siete participantes con enseñanza superior completa o incompleta (Grupo 2). Solamente tres mujeres hacían uso consistente del preservativo masculino como medida preventiva de IST/SIDA. El uso inconsistente del condón fue justificado por la presencia, en el contexto relacional, del compromiso de exclusividad sexual mutua. Valores y creencias acerca del conocimiento sobre el compañero sexual y de la

\footnotetext{
* Mestre em Psicologia pelo Programa de Pós-Graduação em Psicologia da Universidade Federal do Espírito Santo.

\# Professora no Programa de Pós-Graduação em Psicologia da Universidade Federal do Espírito Santo.
} 
confianza invertida en él, orientaban las percepciones de las participantes - de ambos grupos - sobre la necesidad de adhesión a medidas preventivas. Se observó que tales percepciones también estaban estrechamente vinculadas a sus relaciones e implicaciones de género.

Palabras-clave: prevención, infecciones sexualmente transmisibles y sida, género.

No Brasil, a epidemia de HIV/aids - que em seus primórdios se concentrava na Região Sudeste, nos estratos sociais abastados e na população masculina progressivamente se disseminou pelas demais regiões geográficas do país, acometendo estratos empobrecidos e a população feminina. Tal padrão de disseminação, denominado processos de interio-rização, de pauperização e de feminização, denuncia a importância das desigualdades de dimensão coletiva, tais como as socioeconômicas, as étnicas e as de gênero, atuando de modo a condicionar diferentes vulnerabilidades à infecção pelo HIV (Bastos \& Szwarcwald, 2000; Parker \& Camargo Jr., 2000).

Por conformar possibilidades diferentes e, sobretudo, desiguais de acesso a bens materiais e simbólicos entre homens e mulheres, a desigualdade ou hierarquia de gênero desempenha relevante papel no denominado processo de feminização da epidemia ${ }^{1}$. Entre outros aspectos dessa hierarquia, encontra-se a "dupla moral sexual", que impõe mais restrições à expressão sexual das mulheres e maior tolerância às relações extraconjugais dos homens. No âmbito das relações afetivo-sexuais, tal valoração moral estabelece uma subordinação da mulher, que dificulta tanto a negociação pela adesão a medidas preventivas em si como uma decisão que lhe favoreça (Barbosa, 2003; Bastos, 2001; Parker, 2000).

A sexualidade masculina caracteriza-se como expansiva e quase incontrolável, enquanto a feminina é percebida como objeto do controle masculino. Nesse sistema machista, as mulheres exercem pouco ou nenhum direito em relação à expressão sexual dos homens, enquanto estes exercem um poder quase absoluto sobre o comportamento sexual das mulheres (Parker, 2000, p. 81).

Perante tais contornos da epidemia de HIV/aids, em particular, a vulnerabilidade diferencial da mulher,

1 Pesquisas sobre a evolução da epidemia apontam para uma diminuição e estabilização da disseminação entre homossexuais e usuários de drogas injetáveis. Entretanto, o percentual de casos registrados entre mulheres, além de superar o registrado entre homens, apresenta-se em ritmo de crescimento, principalmente entre aquelas de baixa escolaridade, que não ultrapassam o ensino fundamental (Brasil, 2004; Espírito Santo, 2003). objetivou-se conhecer como esta vivencia ${ }^{2}$ a prevenção de infecções sexualmente transmissíveis (IST) e Aids em suas relações afetivo-sexuais. Uma vez que os valores morais estão na base destas relações e variam de acordo com o contexto sócio-histórico em que são instituídos, o conhecimento desses valores, contextualizado em determinados grupos, torna-se relevante para tomadas de decisão e direcionamento das políticas públicas em saúde.

\section{SITUANDO A PROBLEMÁTICA}

A literatura analisada ressalta algumas concepções e valores predominantes nas vivências afetivo-sexuais da maioria dos grupos pesquisados, entre os quais a relação estável - mantida com um único parceiro fixo - aparece como o principal fator associado à dispensa de prevenção (não-uso ou uso inconsistente do preservativo masculino). ${ }^{3}$ (Guimarães, 2001; Miranda, Gadelha \& Szwarcwald, 2005; Monteiro, 2002). Pesquisas desenvolvidas por Jiménez, Gotlieb, Hardy \& Zaneveld (2001) e Pirotta (2002) mostram que a adesão a medidas preventivas é mais freqüente entre mulheres jovens e universitárias nas ocasiões de iniciação sexual e de relações eventuais e/ou de início de relações. A partir do momento em que o contexto relacional é vivenciado como estável, o preservativo masculino, utilizado até então como dispositivo de proteção, é substituído pelo dispositivo contraceptivo oral (pílula). Na análise destes autores, a concepção de

2 A expressão "vivenciar" é usada no presente por abranger, de forma mais ampla, os modos de subjetivação contemporâneos no tocante às relações afetivo-sexuais. $\mathrm{O}$ vivenciar implica não somente aspectos objetivos da relação (como comportamentos observáveis), mas também valores e crenças transmitidos, muitas vezes, como sentimentos e afetações nem sempre facilmente objetiváveis.

3 Em Pesquisa com a população sexualmente ativa IBOPE, desenvolvida pelo Ministério da Saúde através do Programa Nacional de DST e Aids, estabeleceu-se como uso consistente do preservativo sua utilização em todas as práticas sexuais durante os últimos seis meses anteriores à pesquisa. (Brasil, 2003). Na presente, utilizamos o mesmo referencial, e a expressão inconsistente refere-se ao uso ocasional ou intermitente do preservativo. 
estabilidade, sustentada por valores como confiança, fidelidade e respeito mútuos, torna desnecessária a proteção contra doenças, permanecendo apenas a preocupação contraceptiva.

Estudos entre estratos de nível socioeconômico baixo observaram que o conhecer sobrepõe-se à categoria estabilidade na lógica de proteção, com o favorecimento de um parceiro conhecido sobre um estranho. Tal crença, de que o familiar protege, autoriza a dispensa do preservativo, mesmo nas primeiras práticas sexuais com o novo parceiro, caso este fosse conhecido na comunidade mediante contextos tais como o da família, dos pares, do trabalho ou da religião. $\mathrm{O}$ conhecer/confiar refere-se a valores como rapaz caseiro, sossegado, não de ficar na rua, quieto, não mulherengo. (Guimarães, 2001; Monteiro, 2002).

A associação entre familiaridade ou proximidade e segurança, o "conhecer" e a dispensa de prevenção está enraizada em antigos valores e vem sendo analisada por diversos autores. Gogna e Ramos (1999) se referem às estratégias leigas de prevenção, em contraste com as oficiais. Guimarães (1994; 1996; 2001) e Monteiro (1999; 2002) as entendem como vieses das lógicas de proteção particulares, que guiam e organizam as trajetórias afetivo-sexuais de homens e mulheres das classes populares, e se distinguem do discurso preventivo - em grande parte, comprometido com o ideário moderno individualizante e racional. Entretanto, estas análises podem se tornar reducionistas, caso não se considere que tais "vieses particulares" de proteção foram reforçados pelas medidas preventivas oficiais que, durante anos, se apresentavam estreitamente vinculadas à noção de promiscuidade sexual - atinente a práticas sexuais com parceiros múltiplos e desconhecidos (Loyola, 1994).

A relação entre a confiança - outro valor que se destaca nos grupos pesquisados - e a percepção de risco está presente tanto nos estudos com mulheres como naqueles com homens. Na maioria das pesquisas com homens, ocorre uma distinção moral entre "donas de casa" e "mulheres da rua". As primeiras são associadas a sentimentos de confiança, limpeza, pureza e honestidade, ou seja, o grupo das caseiras e confiáveis, as namoradas, moças de família, tímidas e quietas. $\mathrm{O}$ segundo grupo, considerado de risco, refere-se às "vadias", "safadas", "mulheres da noite" ou "sujas", com as quais se deve usar preservativo, uma vez que são não-confiáveis e possíveis portadoras de doenças. (Almeida, 2002; Gogna \& Ramos, 1999; Monteiro, 1999, 2002; Silva, 2002).

Tais dicotomias morais, consideradas por Damatta (1997, 2000) como categorias sociológicas, baseiam-se nos valores de que o espaço moral da casa é sedimentado pelas relações pessoais, afetivas e amorosas, de familiaridade, informalidade, hospitalidade, lealdade, solidariedade, harmonia, calmaria e segurança. Em oposição a casa, a rua é regida por leis universais, vinculadas à individualidade, formalidade, indiferença, anonimato, trabalho, malandragem, movimento e perigo.

Neste debate, Giddens (1991, 1993, 1997) tem trazido importantes considerações sobre as transformações dos sentidos de risco e confiança na contemporaneidade, uma vez que o contraste entre modernidade e tradição não ocorre numa delimitação absoluta, mas é contextual e marcado por diferentes combinações. Nas sociedades pré-modernas ou tradicionais, as interações sociais estão fundamentadas na comunidade particular em que se vive, cujos limites espaciais provêm da estabilidade ao longo do tempo. A extensão da confiança para pessoas pouco conhecidas ocorre por intermédio da extensão do "familiar", isto é, da identificação de laços de parentesco ou do engajamento em encontros rituais, que conferem integridade às tradições e garantem sua preservação. Por seu turno, os ambientes de risco estão, principalmente, ligados às vicissitudes do mundo físico (Giddens, 1991).

Em condições de modernidade, o risco está, em geral, associado à ação humana. Embora permaneçam ligados às relações familiares, os contextos relacionais podem ser atravessados por movimentos de democratização, que preconizam o debate aberto entre as partes, em contextos relacionais igualitários. Direitos e deveres não são simplesmente presumidos, mas negociados; da mesma forma que a confiança é um compromisso ativo, não mais tácito e baseado nos valores morais consolidados por laços familiares.

Essa liberdade de negociação e abertura, fundamental nas relações igualitárias (não somente de gênero), também aparece sob tensão na contemporaneidade. Se, por um lado, ocorrem movimentos sociais crescentes por maior abertura e respeito aos direitos humanos - movimentos gay, feminista, negro, entre outros - ainda se vive em uma sociedade com forte herança dos movimentos normatizantes advindos da razão científico-instrumental. Destaca-se aqui o movimento higienista e a racionalidade médica na disciplina e controle dos corpos, das sexualidades e de modelos do viver saudável, dentro de parâmetros de normalidade 
moralmente preestabelecidos. Por exemplo, sob a égide desse paradigma, a causa da aids seria atribuída a uma falha moral do indivíduo, que se comporta de modo a colocar-se em risco.

\section{MÉTODO}

Trata-se de um estudo de abordagem qualitativa, realizado com mulheres na faixa etária de 20 a 35 anos, agrupadas segundo o nível de instrução formal. Um grupo se constituiu de cinco participantes: duas com ensino fundamental completo e três com ensino médio completo (Grupo1). O outro reuniu sete participantes: cinco com ensino superior incompleto e duas com ensino superior completo (Grupo2). Destas, uma havia se graduado em Enfermagem e outra em Geografia. Dentre as participantes com ensino superior incompleto, todas já tendo cursado mais da metade do curso, havia estudantes de Psicologia (três), de Pedagogia e de Direito. O critério nível de instrução foi utilizado devido à maior incidência da aids entre grupos com menos anos de instrução formal (conforme pesquisas citadas), principalmente entre mulheres com até o ensino fundamental. $\mathrm{O}$ padrão estabelecido pelo Ministério da Saúde, adotado neste estudo, não faz distinção entre nível médio e fundamental (nota de rodapé 1). A delimitação da idade decorreu da constatação (e preocupação) de que, nesse estrato etário específico, o percentual de casos de aids notificados entre mulheres foi bem superior ao dos homens (Espírito Santo, 2003).

Optou-se por abordar as participantes em uma unidade básica de saúde (UBS), integrada à rede municipal do Sistema Único de Saúde (SUS), tendo em vista sua competência e responsabilidade na prevenção de IST/Aids, além de operar a partir de uma demanda espontânea da população. A UBS Raul Oliveira Neves foi eleita por se localizar em Jardim Camburi, bairro no qual se registrou o maior número de casos de aids no município desde o ano de 2002 (Campos, 2003). O contato com as mulheres ocorreu no Programa de Planejamento Familiar, que prevê, além dos exames preventivos do câncer de colo de útero e de mama, reuniões grupais com as usuárias, facilitando o alcance de um número maior de possíveis participantes. Nessas reuniões, as mulheres foram informadas sobre $\mathrm{o}$ estudo e convidadas a participar, voluntariamente. Além desse convite feito diretamente pela própria pesquisadora nos grupos, algumas participantes foram indicadas por profissionais que ali trabalhavam (utilizando como critério assiduidade e interesse de algumas mulheres) e por intermédio da rede de sociabilidade pessoal ${ }^{4}$, em particular, para a constituição do grupo de universitárias. Estas possuíam assistência privada e não faziam uso exclusivo dos serviços da UBS, o que dificultava o acesso através das reuniões.

A coleta de dados foi baseada na técnica de grupo focal, que consiste na reunião de um pequeno número de pessoas para discussão coletiva e livre sobre um tema em especial - no caso "relacionamentos afetivo/sexuais e prevenção de DST/Aids" - indicado pelo pesquisador (Stewart \& Shamdasani, 1990). A análise dos dados é baseada na vivência (ver nota de rodapé 2) das participantes, transmitida através do debate, técnica que recomenda formações grupais com um número em torno de cinco a 12 componentes, de modo que a discussão seja representativa e, ao mesmo tempo, não se torne caótica com um número excessivo de falas e exposições. Ao final dos grupos, as mulheres foram convidadas a participar de uma entrevista individual - no dia, horário e local que lhes fossem convenientes - o que permitiu a realização de doze entrevistas semidirigidas, em que alguns pontos mais relevantes do debate grupal foram retomados, assim como surgiram temas ou explanações, advindos da entrevistada, que não ocorreram no grupo.

A análise do material ocorreu em três etapas: préanálise, exploração do material e o tratamento final de inferência e interpretação. Denominada Análise de conteúdo, envolve procedimentos sistemáticos e objetivos de descrição sobre o conteúdo de uma mensagem, com o intuito de dispor alguma inferência acerca das condições de sua produção e recepção. Pretende-se ir além dos conteúdos manifestos e explicitar aquilo que se encontra velado nas enunciações (Bardin, 1977). No caso de uma análise qualitativa, em que se privilegia não somente a frequiência, mas também a presença ou ausência de certos elementos na mensagem, esse processo compreende o recorte - escolhas das unidades de

4 Expressão utilizada em pesquisas científicas para designar o procedimento em que algumas participantes do estudo indicam pessoas conhecidas que poderiam estar também participando tanto de entrevistas como na formação dos grupos, conforme procedimento previsto pelo estudo. Este tipo de procedimento é particularmente recomendado em se tratando de técnicas grupais, pois as participantes sentem-se mais à vontade para debater sobre suas vivências junto a seus pares ou pessoas com as quais se identificam. 
registro, e a classificação e agregação - escolha das categorias ou categorização. Nesta investigação, a unidade de registro foi o tema. A análise temática consistiu em descobrir os 'núcleos de sentido' que compõem a comunicação e cuja presença, ou freqüência de aparição, foi significativa para o objetivo analítico traçado (Bardin, 1977). Após essa etapa de exploração do material se investiu no tratamento dos resultados, na inferência e na interpretação. Minayo (2000) compreende que “(...) no labor da interpretação não existe última palavra (...)” (p. 222). Nesse sentido, a interpretação dos resultados apresentados a seguir deve ser avaliada como algo inacabável ou em permanente ressignificação; um estatuto provisório imanente a toda produção de conhecimento.

\section{RESULTADOS}

\section{Características gerais dos dois grupos}

À exceção de Sílvia ${ }^{5}$, do grupo universitário (Grupo2), as demais participantes estavam engajadas em relações afetivo-sexuais consideradas estáveis, seja em uniões formais ou consensuais seja em namoro. Tanto no grupo de ensino fundamental ou médio (Grupo1) como no grupo de ensino superior completo ou incompleto (Grupo2), as infecções às quais estavam comumente sujeitas, como, por exemplo, Candidíase, não eram percebidas como potencialmente transmissíveis pelo contato sexual. Apenas Ana (Grupo1) relatou a ocorrência, quatro anos atrás, de uma IST, o Condiloma Acuminado ${ }^{6}$ e, após tratamento, passou a fazer uso de modo consistente do preservativo masculino com seu parceiro, para a prevenção de IST/Aids.

No Grupo1 encontrou-se maior adesão ao preservativo masculino, uma vez que Ana, Gilda e Flávia faziam uso consistente de tal dispositivo. Entretanto, apenas Ana e Gilda o faziam com o objetivo explícito de prevenção contra IST/aids; diferentemente, Flávia o utilizava apenas como o contraceptivo de sua preferência. No Grupo2, apenas Sílvia, que não tinha uma relação estável, fazia uso

Serão utilizados nomes fictícios das participantes.

6 Condiloma Acuminado ou "Crista-de-galo" é a expressão clínica da infecção pelo vírus do Papiloma Humano (HPV). A infecção torna-se visível na forma de lesões e verrugas na área genital e está associada ao desenvolvimento de câncer de útero, vulva, vagina e ânus na mulher, e de pênis e ânus no homem (Brasil, 1999). consistente com propósitos preventivos, em suas relações eventuais. Das doze participantes, quatro, Júlia (Grupo1), Lúcia, Maria e Nádia (Grupo2) em momento algum haviam usado, com seus últimos parceiros, o preservativo masculino com a intenção de prevenir IST/aids. Oito delas - Ana, Eva, Flávia e Gilda (Grupo1), e Paula, Rita, Silvia e Tânia (Grupo2) - haviam feito uso consistente de preservativo como medida preventiva, entretanto apenas o fizeram por um período inicial, que variou de um mês a um ano.

A importância da testagem anti-HIV se mostrou mais consistente no Grupo1, no qual todas as mulheres já a haviam realizado: Ana, Flávia e Júlia a fizeram na ocasião do acompanhamento pré-natal, enquanto Eva e Gilda faziam-na periodicamente. No Grupo2, quatro participantes (Lúcia, Maria, Nádia e Paula) admitiram nunca ter realizado a testagem anti-HIV, uma vez que esta jamais fora solicitada pelos ginecologistas dos serviços privados que freqüentavam. Rita e Tânia, desse grupo, já a haviam realizado, porém apenas Rita a fazia regularmente.

Em ambos os grupos, a aceitabilidade do preservativo feminino se apresentou reduzida, principalmente por seu formato, encaixe e posicionamento no corpo. Todas as participantes declararam preferência pelo preservativo masculino.

\section{Sobre a necessidade de prevenção: o conhecer e o confiar}

A não-adesão a medidas preventivas (ou adesão apenas no início do relacionamento), verificada entre a maioria das participantes, foi justificada pela crença de estarem engajadas em relações afetivo-sexuais estáveis, nas quais pressupunham a exclusividade sexual mútua. Sustentaram que esse cuidado preventivo era prescindível em suas relações, uma vez que tinham um único parceiro e acreditavam que este não tivesse outra(s) parceira(s). Suas concepções de risco estavam, em grande parte, vinculadas à multiplicidade de parceria, passível de acontecer quando não há compromisso de exclusividade ou quando este compromisso não é mantido.

\footnotetext{
"[Não previne] Pelo fato da gente confiar no parceiro. Eu só fico com ele e ele também não tem tempo pra ficar com outra, não! (...) E não dá margem de desconfiança também não! Porque tudo o que ele faz, ele me fala. Foi isso, foi aquilo. Ele tenta chegar na hora.
} 
Ah! Não! Chegou meia-noite, tava onde? Não tem essa coisa, não!' (Júlia -Grupo2).

"Foi uma coisa [interrupção do uso consistente do preservativo] que não foi conversada! Simplesmente, parece que... Como se a gente já tivesse se conhecendo bem e foi uma coisa que não foi falada, mas era como se já tivesse tipo um pacto mesmo assim, sabe? Um pacto de fidelidade e a gente nem conversou nada, eu não falei nada e nem ele, e foi ficando assim!" (Paula Grupo2).

O termo confiar foi empregado por participantes de ambos os grupos em referência às relações afetivosexuais nas quais não somente estaria firmado um compromisso de exclusividade sexual mútua, mas supostamente este estaria sendo cumprido. A vivência do risco - com a adesão e/ou permanência do uso do preservativo - implicaria a possibilidade de rompimento de tal compromisso, pondo em questão a fidelidade do parceiro. Por essa razão, Flávia (Grupo1) - que fazia uso consistente do preservativo em sua união formal - insistiu em esclarecer que o fazia em sua função exclusivamente contraceptiva. Observa-se, nos exemplos acima, um predomínio dos valores tradicionais, em que a confiança é presumível, tácita, advinda do aspecto temporal da relação e não fruto de um diálogo igualitário (Giddens, 1991). Esse acordo tácito aparece sob um fundo de dúvida - imediatamente negada - sob negrito nas falas, fruto de uma confiança unilateral no parceiro, em que o conhecer remete-se ao familiar, dispensando negociações e trocas através de diálogos abertos ou explicitação de dúvidas.

Não obstante, a concomitância de valores tradicionais e modernos produz contradições e particularidades nas diversas formas de conceber e vivenciar a relação de confiança. Assim, Eva (Grupo1), Rita e Tânia (Grupo2) não se basearam numa confiança presumível, mas exigiram a testagem anti-HIV, como condição para a dispensa do preservativo.

"Era pra eu ver mesmo! O anti-HIV, porque eu pedi e falei: "Você vai ao médico que você quiser e pede a ele pra fazer todos os exames de sangue DST, HIV, pra ver se não tem alguma doença e tal". Foi conversado mesmo! Eu pedi pra ele, sim! Aí, minhas colegas na faculdade falavam: "Não acredito que você vai ter coragem de pedir! Gente! Mas eu tenho que pedir! Como é que eu faço se eu não pedir? Como é que eu vou ficar com ele? Como eu vou ficar tranqüila, se eu não conheço ele?" (Rita - Grupo2).

Percebe-se, claramente, a diferença do sentido conhecer para Rita, que não era automaticamente presumível em função de uma relação estável. É interessante observar a reação das colegas perante tal atitude, como se fosse uma ofensa implícita ao caráter moral do parceiro. Entretanto, para Rita, a franqueza e $o$ diálogo eram fundamentais para o conhecimento e conquista de confiança (ficar tranqüila). A presença da lógica tradicional do conhecer, como familiar ou próximo, tende, porém, a prevalecer entre as participantes, uma vez que a maioria não considerou importante nem o diálogo nem o aval da testagem para interromper a prevenção.

\footnotetext{
"Aconteceu sem [camisinha] e foi ficando, né? Apesar de ser um ato irresponsável, mas ele sempre foi muito tranqüilo, com uma vida sexual muito tranqüila, eu também. Apesar, isso não justifica, mas aconteceu de rolar sem e ficamos (...) Ele sempre teve uma vida tranqüila, né? Ele me fala isso e a família dele também me fala que ele nunca foi namorador, sempre muito caseiro!" (Flávia Grupo1).
}

Nesse enunciado, assim como em alguns exemplos anteriores, observa-se a vivência de confiança nas relações afetivo-sexuais pautada em avaliações morais e tradicionais sobre o parceiro, respaldadas, no caso, pelo entorno familiar. $\mathrm{O}$ conhecer é associado à proximidade e ao familiar, enquanto a confiança advém do caráter bom, tranqüilo, caseiro. Ao lado dessa lógica tradicional aparece a tensão, claramente explicitada na fala (ato irresponsável, não se justifica) com os valores contemporâneos que apelam para relações dialógicas e decisões mais "responsáveis" entre o casal.

Entre oito participantes (três do Grupo1 e cinco do Grupo2) foram registradas apreciações de seus parceiros (determinantes na avaliação de risco) de estatuto intrinsecamente moral, que tinham por objeto a qualificação do caráter sob os valores dicotômicos e essencialistas de Bem e Mal. Tais apreciações também foram analisadas como categorias sociológicas de casa e rua desenvolvidas por DaMatta (1997, 2000).

\section{Relações e implicações de gênero}

Verificou-se que, no Grupo 1, a adesão a medidas preventivas, no início das relações afetivo-sexuais e eventual continuidade, era proposta com mais frequiência pelas mulheres. Dentre as cinco 
participantes deste Grupo, quatro apregoaram explicitamente o imperativo da iniciativa feminina no processo de adesão. Para elas, cabia à mulher "impor" ao homem toda e qualquer medida preventiva que considerasse necessária, ainda que à custa da continuidade da relação. Foi muito difícil! Ele não aceitava, como até hoje não aceita! Mas eu falo: "Não usa então camisinha na rua, mas comigo, em casa, tem que usar!" (Ana). Esse tom enfático se destacava no Grupo1. Então, eu acho assim se a mulher quer usar, e se o marido falar que não, então eu acho que a mulher tem que falar: "Não tem camisinha, não tem sexo!" (Flávia).

Entre as participantes do Grupo2, esse imperativo não apareceu em tal intensidade. Apenas Sílvia - única participante sem parceria estável - declara enfaticamente não abrir mão do preventivo. Eles até tentam me convencer: "Mas eu não vou gozar!" Mas pra mim não adianta não! Se ele não tiver camisinha, eu não transo! Tranqüilo pra mim. Quando não tem, não faz hoje, outro dia faz. Rita e Tânia cederam à insistência dos parceiros em deixar de usar o preventivo, porém exigiram que estes fizessem a testagem anti-HIV. À unanimidade, as participantes desse grupo relataram que seus parceiros não gostavam de usar preservativo e três delas (Maria, Nádia e Tânia) compartilhavam a mesma opinião. A tendência geral do grupo era de não insistir ou impor o uso consistente de preservativo, em especial, no início da relação afetivo-sexual. Quatro delas alegavam nunca ter tido preocupação com a prevenção contra doenças, até porque isso nunca havia sido colocado em suas consultas ginecológicas. A maioria dessas participantes apresentou um assentimento à vontade do parceiro, apontando para uma posição mais submissa, consoante com as expectativas tradicionais de gênero.

\section{CONSIDERAÇÕES FINAIS}

Os resultados corroboram, em parte, a literatura da área no que concerne ao uso inconsistente de preservativo em relações estáveis, justificado por crenças e valores morais atrelados ao conhecer/confiar. Entretanto, traz à luz alguns dados importantes pouco discutidos e/ou abordados até o momento.

1. Tais valores morais tradicionais vêm sendo, já há algumas décadas, denunciados em sua impropriedade no tocante aos modelos existenciais idealizados e predominantes nas sociedades ocidentais. Transcendentes, estes valores pressupõem essências e verdades totalizantes (o
Bem e o Mal) a partir das quais a vida (relações humanas, modos de ser) deve ser julgada, não cabendo reflexões ou questionamentos, uma vez apresentados como naturais. Em contraposição, os modos de subjetivação contemporâneos propõem valores éticos, uma avaliação da vida em sua expansão permanente e diversidade de modos existenciais. Substitui-se a crença em causalidades externas e universais por reflexões sobre nossos próprios encontros e nossas potências singulares para agir. Segundo Giddens (1991), a temporalidade tradicional é regida pela lógica da repetição, em que o passado desempenha uma forte influência no tempo presente, refletida na confiança quase inabalável em sistemas tidos como estáveis, conhecidos e naturais. Diferentemente dessa "fé na probidade moral" das relações tradicionais, a confiança entre pessoas tende, na modernidade, a se tornar um projeto a ser trabalhado pelas partes envolvidas - uma vez que o presumível estável e conhecido torna-se objeto de suspeição - que implica abertura e responsabilidade perante suas próprias opções. Essa tensão entre a fé tradicional e a convocação moderna para a auto-reflexão e autodeterminação, princípios da autonomia e respeito nos relacionamentos, aparece claramente nas falas das participantes, apontando para outras formas e possibilidades de vivenciar as relações afetivosexuais. A observação desses embates é fundamental para a compreensão das mudanças nas relações de gênero calcadas, fundamentalmente, em valores morais (sempre externos). Aponta para a experimentação dessas mulheres da possibilidade de divergir e criar modos próprios de avaliar e refletir criticamente sobre si e o entorno. A sustentação, por parte dos profissionais, dessa potência própria a cada ser humano funciona como importante motor de transformação e ruptura com os valores morais tradicionais constantemente reforçados nas relações cotidianas.

2. Diferentemente dos resultados encontrados por pesquisas desenvolvidas com mulheres de classes populares, este grupo se mostrou, no presente estudo, fora dos padrões de submissão predominantes. Ao contrário, suas componentes foram enfáticas em defender uma posição ativa da mulher no tocante à imposição de dispositivos de proteção nas relações afetivo-sexuais. Apresentaram uma reflexão crítica e clara da hierarquia de gênero e das características do 
homem nesta relação, que "são muito relaxados $e$ despreocupados; não estão nem aí pra pegar ou passar doença”, cabendo, por isso, à mulher tomar a decisão. Não defendem um diálogo igualitário isso lhes parece impossível perante a postura machista do parceiro - mas a necessidade de uma imposição e firmeza por parte da mulher. A "dupla moral sexual" analisada por Parker (2000) parece questionada por essas mulheres, pelo menos no tocante à não-submissão ao desejo do parceiro de não usar camisinha. Esse questionamento aparece associado a uma preocupação com a própria saúde, com a responsabilidade de cuidar de si. Esse diferente posicionamento na relação de gênero aponta novas composições entre a tensão tradicional e a moderna e, associado a uma preocupação com a saúde, nos remete a outra consideração.

3. Não se pode deixar de trazer para reflexão um tema que esteve presente, mesmo que indiretamente, nos debates dos grupos, qual seja o dos Serviços de atendimento em saúde à mulher $\mathrm{e}$ os valores arraigados a alguns profissionais. As mulheres de classe popular, que são atendidas pelo SUS, freqüentam uma UBS onde encontram um espaço de trocas e debate sobre prevenção, em que são constantemente provocadas e alertadas sobre seus riscos e sua saúde. Estas apresentaram uma leitura crítica da realidade e das relações afetivo-sexuais - valores de gênero - bem diferenciadas do Grupo2. Contrariamente, estas últimas, que freqüentam serviços ginecológicos particulares, mostraram um desconhecimento bem maior tanto dos valores morais presentes na hierarquia de gênero (essa tensão transparecia indiretamente nos relatos sobre confiar/conhecer e as dúvidas subjacentes) quanto em suas avaliações de risco. A maioria relatou nunca ter sido alertada pelo médico sobre a possibilidade de contrair doenças ou a necessidade de prevenção. Tais dados nos levam a pensar sobre o desconhecimento dos profissionais de setores privados da incidência crescente de aids entre mulheres. Pode-se também pensar na pregnância de valores morais que relacionam a doença a pobreza, sujeira, imoralidade, entre outras causas, das quais sua clientela estaria isenta. Como em sua maioria as pesquisas nacionais são voltadas para as classes populares, esse silêncio dos profissionais do setor privado junto a suas clientes não deixa de surpreender e preocupar.
Finalizando, estes resultados apontam para transformações importantes nas relações afetivosexuais, advindas das vivências de tensão entre os valores morais tradicionais e as novas demandas éticas contemporâneas, que provocam outras leituras e composições nas relações de gênero. Atentar para tais embates é fundamental para evitar as capturas, sempre presentes, no cotidiano do trabalho e intervenções em saúde preventiva. Trata-se de uma revolução nos modos de conceber/estar societários, que somente será possível na medida em que as relações de dominação deixarem de ser veiculadas como algo natural e imutável. É preciso desconstruir as dicotomizações presentes na mídia e demais instituições - de alguma forma já tensionadas pelas participantes desse estudo para que se possam pensar outras possibilidades de prevenção; modos de prevenção menos restritivos $e$ impositivos, mas negociados na abertura cotidiana entre pares respeitados na igualdade de suas potências ativas e criativas, porém, singulares a cada modo próprio (e não desvalorizado) de estar na vida.

\section{REFERÊNCIAS}

Almeida, C. C. L. de. (2002). Risco e saúde reprodutiva: a percepção dos homens de camadas populares. Caderno Saúde Pública, 18(3), 797-805. Disponível em: <http:// www.scielo.br>. (Acesso em 07/102003).

Barbosa, R. M. (2003). Um olhar de gênero sobre a epidemia de aids. Em E. Berquó (Org). Sexo e vida: panorama da saúde reprodutiva no Brasil. (pp. 339-389). Campinas: Editora da UNICAMP.

Bardin, L. (1977). Análise de Conteúdo. Lisboa: Edições 70.

Bastos, F. I. (2001). A feminização da epidemia de Aids no Brasil: determinantes estruturais e alternativas de enfrentamento. Coleção ABIA: Saúde Sexual e Reprodutiva, 3. Rio de Janeiro: ABIA. Disponível em: <http://www.abiaids.org.br〉. (Acesso em 20/09/2003).

Bastos, F. I. \& Szwarcwald, C. L. (2000). Aids e pauperização: principais conceitos e evidências empíricas. Caderno Saúde Pública, 16(1), 65-76. Disponível em: <http://www. scielo.br>. (Acesso em 07/04/2004).

Brasil (1999). Manual de controle das doenças sexualmente transmissíveis. Brasília: Ministério da Saúde; Secretaria de Vigilância em Saúde; Programa Nacional de DST e Aids. Disponível em: <http://www.aids.gov.br/assistencia/ mandst99>. (Acesso em 03/12/2004).

Brasil (2003). Pesquisa com a população sexualmente ativa IBOPE, janeiro de 2003. Brasília: Ministério da Saúde; Secretaria de Vigilância em Saúde; Programa Nacional de DST e Aids. Disponível em: <http://www.aids.gov.br/ final/biblioteca>. (Acesso em 07/10/2003).

Brasil (2004). Boletim Epidemiológico DST/AIDS. Ano I, n.1, janeiro a junho de 2004. Brasília: Ministério da Saúde, Secretaria de Vigilância em Saúde, Programa Nacional de 
DST e Aids. Disponível em: <http://www.aids.gov.br/ final/biblioteca>. (Acesso em 14/12/2004).

Campos, I. (2003). Apresentação. Em I. Campos (Org.). Uma trajetória capixaba: 10 anos do CR DST/Aids (pp.17-29). Vitória: Prefeitura Municipal de Vitória. Secretaria Municipal de Saúde. Centro de Referência de DST/Aids.

DaMatta, R. (1997, 6a ed.). Carnavais, malandros e heróis: para uma sociologia do dilema brasileiro. Rio de Janeiro: Rocco.

DaMatta, R. (2000, 6 ${ }^{\text {a }}$ ed.). A casa e a rua: espaço, cidadania, mulher e morte no Brasil. Rio de Janeiro: Rocco.

Espírito Santo (2003). Boletim epidemiológico DST/Aids do Espírito Santo, n. 10, março a agosto de 2003. Vitória: Secretaria Estadual de Saúde, Coordenação Estadual de DST e Aids - ES.

Giddens, A. (1991, 2ª ed.). As conseqüências da modernidade. São Paulo: Editora da Universidade Estadual Paulista.

Giddens, A. (1993). A transformação da intimidade: sexualidade, amor e erotismo nas sociedades modernas. São Paulo: Editora da Universidade Estadual Paulista.

Giddens, A. (1997). A vida em uma sociedade pós-tradicional. Em U. Beck, A. Giddens \& L. Scott (Orgs.). Modernização Reflexiva: política, tradição e estética na ordem social moderna. (pp.73-134). São Paulo: Editora da Universidade Estadual Paulista.

Gogna, M. \& Ramos, S. (1999). Crenças Leigas, estereótipos de gênero e prevenção de DSTs. Em R. M. Barbosa \& R. Parker (Orgs.), Sexualidades pelo avesso: direitos, identidades e poder. (pp. 229-248). Rio de Janeiro/São Paulo: IMS-UERJ/Editora 34.

Guimarães, C. D. (2001). Aids no feminino: por que a cada dia mais mulheres contraem Aids no Brasil? Rio de Janeiro: Editora UFRJ.

Guimarães, C. D. (1996). “Mas eu conheço ele!": um método de prevenção do HIV/aids. Em R. Parker \& J. Galvão (Orgs.), Quebrando o silêncio: mulheres e AIDS no Brasil. (pp. 169-180). Rio de Janeiro: Relume-Dumará/ABIA/IMS - UERJ.

Guimarães, C. D. (1994). Mulheres, sexualidade e aids: um projeto de prevenção. Em A. de O. Costa \& T. Amado (Orgs.), Alternativas escassas: sexualidade e reprodução na América Latina. (pp. 249-281). São Paulo/Rio de Janeiro: PRODIR - FCC/Editora 34.

Jiménez, A. L.; Gotlieb, S. L. D., Hardy, E. \& Zaneveld, L. J. D. (2001). Prevenção de doenças sexualmente transmissíveis em mulheres: associação com variáveis sócio-econômicas e demográficas. Caderno Saúde Pública, 17(1), 55-62. Disponível em: <http://www.scielo.br>. (Acesso em 12/07/2003).

Loyola, M. A. (1994). Aids e prevenção da Aids no Rio de Janeiro. Em M. A. Loyola (Org.), Aids e sexualidade: $o$ ponto de vista das ciências humanas. (pp. 19-72). Rio de Janeiro: Relume-Dumará/UERJ.

Minayo, M. C. de S. (2000, $7^{\mathrm{a}}$ ed.). $O$ desafio do conhecimento: pesquisa qualitativa em saúde. São Paulo/Rio de Janeiro: HUCITEC/ABRASCO.

Miranda, A. C., Gadelha, A. M. J. \& Szwarcwald, C. C. (2005). Padrão de comportamento relacionado às práticas sexuais e ao uso de drogas de adolescentes do sexo feminino residentes em Vitória, Espírito Santo, Brasil, 2002. Caderno Saúde Pública, 21(1) 207-216. Disponível em: <http://www.scielo.br>. (Acesso em 23/04/2005).

Monteiro, S. (1999). Gênero, sexualidade e juventude numa favela carioca. Em M. L. Heilborn (Org.), Sexualidade: $o$ olhar das ciências sociais. (pp. 117-145). Rio de Janeiro: Jorge Zahar.

Monteiro, S. (2002). Qual prevenção? Aids, sexualidade e gênero em uma favela carioca. Rio de Janeiro: Fiocruz.

Parker, R. \& Camargo Jr., K. R. de. (2000). Pobreza e HIV/AIDS: aspectos antropológicos e sociológicos. Caderno Saúde Pública, 16(1) 89-102. Disponível em: <http://www.scielo.br>. (Acesso em 07/04/2004).

Parker, R. (2000). Na contramão da Aids: sexualidade, intervenção, política. Rio de Janeiro/São Paulo: ABIA/Editora 34.

Pirotta, K. C. M. (2002). Não há guarda chuva contra o amor: estudo do comportamento reprodutivo e de seu universo simbólico entre jovens universitários da USP. Tese de Doutorado, Departamento de Saúde MaternoInfantil da Faculdade de Saúde Pública, Universidade de São Paulo, São Paulo. Disponível em: <http://www.teses.usp.br>. (Acesso em 15/01/2004).

Silva, C. G. M. da. (2002). O significado e as estratégias para prevenção da Aids entre homens casados. Revista de Saúde Pública, 36(4), 40-49. Disponível em: <http://www.scielo.br>. (Acesso em 07/10/2003).

Stewart, D. W. \& Shamdasani, P. N. (1990). Focus groups: Theory and practice. California: Sage.

Recebido em 27/10/2005 Aceito em 03/04/2006

Endereço para correspondência: Melissa Mattos Amorim. R. José Neves Ciprestes, n. 1091, apt. 401, Jardim da Penha, CEP 29060-300,Vitória-ES. E-mail: melissamorim@terra.com.br 